\title{
Integrating men into the reproductive health equation: Acceptability and feasibility in Kenya
}

Esther G. Muia

Violet Kimani

Ann Leonard

Follow this and additional works at: https://knowledgecommons.popcouncil.org/departments_sbsr-rh

Part of the Demography, Population, and Ecology Commons, Family, Life Course, and Society Commons, and the International Public Health Commons How does access to this work benefit you? Let us know!

\section{Recommended Citation}

Muia, Esther G., Violet Kimani, and Ann Leonard. 2000. "Integrating men into the reproductive health equation: Acceptability and feasibility in Kenya," Robert H. Ebert Program on Critical Issues in Reproductive Health Publication Series. New York: Population Council. 
THE ROBERT H, EBERT PROGRAM
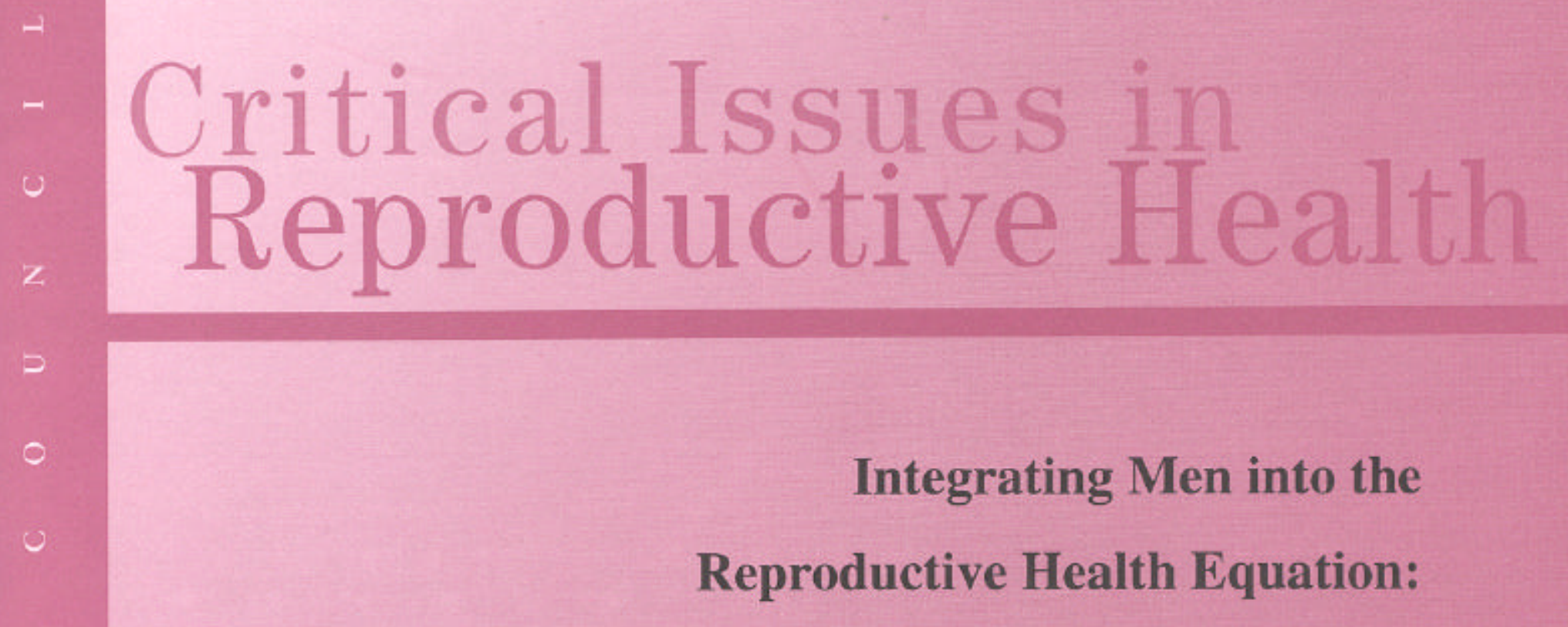
Acceptability and Feasibility in Kenya 


\section{Integrating Men into the}

Reproductive Health Equation: Acceptability and Feasibility in Kenya 



\title{
Integrating Men into the \\ Reproductive Health Equation: \\ Acceptability and Feasibility in Kenya
}

\author{
Esther Muia ${ }^{1}$ \\ Joyce Olenja ${ }^{2}$ \\ Violet Kimani ${ }^{2}$ \\ Ann Leonard ${ }^{3}$
}

\footnotetext{
${ }^{1}$ Robert H. Ebert Program, Population Council, Nairobi

${ }^{2}$ Department of Community Health, University of Nairobi

${ }^{3}$ Robert H. Ebert Program, Population Council, New York
} 
The Population Council is an international, nonprofit, nongovernmental institution that seeks to improve the wellbeing and reproductive health of current and future generations around the world and to help achieve a humane, equitable, and sustainable balance between people and resources. The Council conducts biomedical, social science, and public health research and helps build research capacities in developing countries. Established in 1952, the Council is governed by an international board of trustees. Its New York headquarters supports a global network of regional and country offices.

The Council's Robert H. Ebert Program on Critical Issues in Reproductive Health, established in 1988, responds to an awareness that many important reproductive health problems - and the ways women experience them — have been neglected by policymakers, program planners, and practitioners. Currently the Program focuses on several areas that merit special attention: improving the quality of services in reproductive health programs, managing unwanted pregnancy and preventing the consequences of unsafe abortion, devising new approaches to postpartum care to meet the health needs of the mother and child, and designing programs that address sexually transmitted diseases, including AIDS, within the larger context of women's reproductive health.

\section{(2) Population Council}

The Robert H. Ebert Program on

Critical Issues in Reproductive Health Population Council

One Dag Hammarskjold Plaza

New York, NY 10017 USA

Telephone: (212) 339-0500

Fax: (212) 755-6052

E-mail: pubinfo@popcouncil.org

Web site: www.popcouncil.org
East and Southern Africa Region

Population Council

General Accident House

Ralph Bunche Road

P.O. Box 20944

Nairobi, Kenya

Telephone: (011) (254) (2) 713-480/1/2/3

Fax: (011) (254) (2) 713-479

E-mail: pcnairobi@popcouncil.org

\section{(C) 2000 by The Population Council, Inc.}

Any part of this publication may be photocopied without permission from the authors or the Population Council, provided that publication credit is given and that the copies are distributed free. Any commercial reproduction requires prior written permission from the Population Council. 


\section{Acknowledgments}

The authors would like to acknowledge Dr. Bolaji Fapohunda, formerly of the African Population and Health Research Center (APHRC), and Dr. Ayorinde Ajayi for their input in the proposal development. Linda Cushman of Columbia University assisted in developing the questionnaires. Support for the study was provided by the Robert H. Ebert Program on Critical Issues in Reproductive Health. We would also like to thank the staff of both Kenyatta National Hospital and Kakamega Provincial General Hospital for their collaboration in carrying out this study. In particular, we are grateful for the administrative support of Dr. Omondi Ogutu, Head of Obstetrics and Gynecology at Kenyatta National Hospital, and Dr. Ibrahim Amira, Provincial Medical Officer for Western Province at the time this study was carried out. We would also like to thank Mrs. Getrude Shikuku, a matron at Kakamega Provincial General Hospital; Michael Namai, Benta Olouch, and Opondo, research assistants at Kakamega; and Jane Gatune and Francis Kimani, who administered the questionnaires at Kenyatta National Hospital. Data entry was competently handled by Monica Kamiti and Jennifer Liku, who also worked on the analysis.

We are grateful to the John D. and Catherine T. MacArthur Foundation for support of this research study and the report. 



\section{BACKGROUND AND RATIONALE}

The idea of integrating men into the reproductive health equation is rapidly gaining currency and credibility, in part due to a shift in emphasis in the international donor community from pure family planning for demographic reasons to broader reproductive health for human and health reasons. This shift is prompting re-evaluation of the premises and concepts under which programs have been designed, implemented, and evaluated, as it has become evident that a crucial half of the equation — that is, men — has been neglected.

\section{Reproductive Health Services in Kenya}

As in most countries, after the 1994 International Conference on Population and Development (ICPD) in Cairo the term reproductive health has been adapted in Kenya to encompass all services that relate to the sexual and reproductive health of individuals. The Ministry of Health, with technical assistance from various governmental and nongovernmental organizations working in reproductive health locally, has developed a national reproductive health strategy for Kenya. The strategy is a tool to help planners and implementers direct the focus of their work, assess priorities, meet needs, and fill the gaps identified. In addressing gender relations and reproductive rights, the strategy has suggested that "special efforts should be made to emphasize and enhance men's shared responsibility and promote their active involvement in responsible parenthood, responsible sexual and reproductive behavior, promotion of the equal value of children of both sexes and the status of women ... [and] to strengthen the participation of men in the reproductive health program they should be more involved both as service providers and beneficiaries of service." ${ }^{1}$ At this early stage in operationalizing the reproductive health strategy it is important to assess the feasibility of this aspect of the strategy.

Within the health establishment, reproductive health services are divided into three broad categories: preventive, promotive, and curative. Preventive and promotive services include maternal and child health $(\mathrm{MCH})$, including family planning (FP) programs that provide prenatal care, immunizations (pregnant woman and well baby), postnatal care, and family planning services. Curative services include inpatient obstetric and gynecological services and outpatient treatment of sexually transmitted diseases (STDs) or any other obstetric or gynecological problems not requiring admission, including consultant outpatient gynecological clinics.

\section{Problem Statement and Justification for the Study}

In Kenya as elsewhere, it has been observed and documented that men have a significant impact, directly and indirectly, on women's ability to access services and implement regimes of care. Thus far, however, men have been left out of the mainstream of reproductive health services. Most efforts undertaken to date to address the marginalization of men have focused on their involvement in fertility regulation (specifically increased use of condoms and vasectomy). With the shift toward a more comprehensive reproductive health strategy, we

1 The National Reproductive Health Strategy 1997-2010. Ministry of Health, Kenya. 1997. 
now need to determine if men are in fact already participating in a range of reproductive health services and, if so, to what degree. We also need to know which men are and are not participating and why, what women think about men's actual and potential participation, and what service providers think about the greater involvement of men in their services. Answers to these questions will help us develop interventions aimed at appropriately increasing men's participation to a level that is acceptable to men, their partners, and service providers, without in any way compromising women's ability to make reproductive health decisions for themselves.

\section{Study Objectives}

The study's ultimate objective was to improve our understanding of men's actual and potential roles as supportive partners in various phases of reproductive health. This information will be used in the design of strategies to encourage men's greater participation in a variety of reproductive health initiatives in Kenya.

Specifically, the study set out to:

1. Identify the degree to which men currently participate in existing reproductive health services that are focused primarily on women;

2. Assess the attitudes of women, their partners, and service providers toward men already participating in various services related to obstetrical and gynecological care, family planning, and pre- and postnatal care offered at the facility level;

3. Identify the barriers to men's greater participation in obstetrical and gynecological services, family planning, and pre- and postnatal care offered at the facility level; and

4. Determine the degree and type of involvement by male partners that is perceived as desirable by women, their partners, and service providers.

\section{Study Sites}

The study was conducted in two sites: Kenyatta National Hospital in Nairobi (the capital city) and Kakamega Provincial General Hospital for the Western Province in Kakamega. While Nairobi is the most cosmopolitan city in Kenya, Kakamega is more than 90 percent rural. Thus the study was able to compare perspectives in both urban and rural settings.

Kenyatta National Hospital $(\mathrm{KNH})$ in Nairobi is the national referral hospital for Kenya, as well as the oldest and largest teaching institution in the country. It offers a comprehensive array of preventive, promotive, and curative services and has a maternity unit with an average of 25 deliveries per day. $\mathrm{KNH}$ is parastatal (autonomous government-run), with specialist consultants in charge of the different departments. There are medical doctors at different levels, as well as other paramedical staff, including nurses of different cadres.

Kakamega Provincial General Hospital (KPGH) is located in Western Province, which has the highest density of population per square kilometer and the largest average family size in Kenya. This hospital averages 20 deliveries per day. KPGH is the main referral hospital for Western Province. It is operated by the government and is a typical provincial hospital in terms of services provided, infrastructure, and staffing. The area's predominant ethnic group is the Abaluhyia, but because it is the seat of the provincial government for Western 
Province, representatives of other ethnic groups within Kenya can be found working in government ministries. Overall, Kakamega District does not differ greatly from other parts of Western Province or other districts in Kenya as regards women's status. Thus it offered the perspective of a rural and more traditional setting for this study.

\section{STUDY METHODOLOGY}

\section{Study Design}

This descriptive study used a combination of qualitative and quantitative techniques to gather information from the different study populations. Standardized questionnaires were used at the two hospitals to gather information from five study groups:

1. Women admitted for inpatient care;

2. Women receiving outpatient care;

3. Men accompanying women for either in- or outpatient care;

4. Partners of women who did not accompany them to the hospital; and

5. Service providers.

The quantitative study was undertaken in September 1998. A total of 1,188 sampled respondents were approached for the interview, consisting of 701 women, 289 men, and 198 service providers. Of the 194 men who accompanied their partners to the hospital, five refused to be interviewed. With the women's consent, 95 men who did not come to the hospital were followed up, and all completed the questionnaires.

Two trained research assistants were employed at each study site and were stationed there daily for one month. They interviewed both men and women at the site as well as partners in the community who did not accompany women to the hospitals. (Community follow-up was only done when the patients gave their permission for the interview to take place.) At each of the facilities, one of the principal investigators interviewed selected service providers. The investigators also made periodic visits to the sites to oversee data collection.

The principal investigators and a social scientist conducted several focus-group discussions (FGDs) with women and service providers at each site. Given that the study population was recruited from predominantly female-focused services, it was difficult to bring together groups of men at the same place and time. For this reason FGDs involving men were not undertaken within the study.

FGDs were conducted at KPGH in October 1998 and at KNH in December 1998. A total of six groups of between eight and twelve participants were involved in the discussions. The groups included:

- Health providers from each of the stations serving women;

- Women in obstetrics/gynecology inpatient wards;

- Women in maternity wards; and

- Women in family planning clinics. 
FGDs focused on expectations in partnerships, perceptions of actual and desired participation of men in women's reproductive health-seeking behavior, societal and institutional constraints to partner involvement, and communication between partners.

As an initial step, the specific reproductive health services offered at each site were identified by the principal investigators and a list was drawn up showing their locations. Specific note was made of physical and procedural barriers that currently limit or restrict the participation of men, such as clinic/visiting hours and the extent to which men are allowed to accompany their partners into the facilities.

\section{Study Populations}

There were three study populations at each of the two sites:

1. Women seeking obstetrical and gynecological care on an in-and outpatient basis and those attending pre- and postnatal services. All women who came to the health facility seeking the above-mentioned reproductive health services were eligible to be enrolled in the study. Multistage sampling was applied to calculate the minimum number of women to be interviewed in each section, with the result that approximately 300 women would be interviewed at each site.

After obtaining consent, the appropriate questionnaire was administered in person by a trained research assistant at an appropriate time during the woman's stay in the hospital: before discharge for inpatients or, in the case of outpatients, at an appropriate time before they left the particular service. Exempted were any women who were too ill to respond (based on the attending providers' recommendation) or who did not consent to be interviewed.

At each facility three FGDs were held with women receiving reproductive health services using a guide specifically developed for this study. Those who participated were not the same women who were interviewed for the quantitative portion of the study. One FGD involved women seeking inpatient services; the other involved women seeking outpatient services.

2. Men who accompanied their partners for reproductive health services and men who did not. For all women sampled and interviewed at the two facilities, permission was sought to interview their partners. Those who accompanied or were with their partners at any time during a hospital stay were interviewed on-site. Partners who did not visit the facility were interviewed at home or at the workplace only if the patients gave their consent. In some cases, the research assistant actually accompanied the woman home in order to speak to her partner. On obtaining the man's consent, the same research assistant who had interviewed the woman administered a questionnaire to her partner.

3. Service providers. A list of providers currently involved in the provision of reproductive health services was obtained from the administration of each facility. Depending on the number of providers at each site, stratified multistage sampling for the different cadres was used and a minimum number of staff to be interviewed was determined. At each site, 
standardized questionnaires were administered by the research assistants. FGDs, however, were conducted, transcribed, and analyzed by the principal investigators at both sites.

\section{FINDINGS FROM THE QUANTITATIVE STUDY}

This study aimed to improve our understanding of the role of men as supportive partners in reproductive health care in Kenya through application of both qualitative and quantitative techniques. The pertinent findings from the quantitative instruments are presented here.

\section{Respondent Characteristics}

Total respondents sampled numbered 1,188, including 701 women, 289 men, and 198 service providers. Only four women, five men accompanying their partners, and two service providers refused to be interviewed; notably there were no refusals among the 95 men who were followed up in the community (Table 1).

Table 1 Respondents, by site

\begin{tabular}{|l|c|c|c||}
\hline & $\begin{array}{c}\text { Kenyatta National } \\
\text { Hospital (urban) }\end{array}$ & $\begin{array}{c}\text { Kakamega Provincial } \\
\text { General Hospital (rural) }\end{array}$ & Total \\
\hline Women & 303 & 394 & 697 \\
\hline Men at the facility & 122 & 67 & 189 \\
\hline Men followed up & 12 & 83 & 95 \\
\hline Service providers & 101 & 95 & 196 \\
\hline Total respondents & 538 & 639 & 1,177 \\
\hline \hline
\end{tabular}

More than one-third of the women presenting at $\mathrm{KNH}$, the urban site, were accompanied by their partners, while at the rural site just over one-sixth of women's partners accompanied them.

Age. As expected, women seeking reproductive health services tended to be younger, with most respondents aged 40 years and less, while the men ranged from 21 to 50 years of age (Table 2). Providers interviewed ranged in age from 21 to 50 years, with the majority less than 40 years old. 
Table 2 Age of respondents, by site*

\begin{tabular}{|l|l|l|l|l|l|l|}
\hline Respondents & $\mathbf{2 1}$ years & $\mathbf{2 1 - 3 0}$ years & $\mathbf{3 1 - 4 0}$ years & $\mathbf{4 1 - 5 0}$ years & $\mathbf{5 1 - 6 0}$ years & $>\mathbf{6 0}$ years \\
\hline Women at KNH & 34 & 176 & 72 & 17 & 4 & - \\
\hline Women at KPGH & 102 & 212 & 70 & 6 & 1 & 1 \\
\hline Total women & 136 & 388 & 142 & 23 & 5 & 1 \\
\hline Men at KNH & - & 51 & 55 & 20 & 6 & 2 \\
\hline Men at KPGH & 5 & 75 & 53 & 10 & - & - \\
\hline Total men & 5 & 126 & 108 & 30 & 6 & 2 \\
\hline Providers at KNH & - & 49 & 47 & 3 & - & - \\
\hline Providers at KPGH & - & 36 & 33 & 22 & 2 & - \\
\hline Total providers & & 85 & 80 & 25 & 2 & - \\
\hline
\end{tabular}

* Some respondents did not give their age.

It is interesting to note that there were significantly more men and women older than 40 in the urban sample and more than three times as many women younger than 21 in the rural sample. Among service providers, those working in Nairobi were concentrated in the under-40 age group while in Kakamega there was a more variable age range.

Occupation. While most rural women interviewed (59.1 percent) were engaged in farming and small trade, a large proportion of urban women reported that they were students or unemployed (45.2 percent) (Table 3). Only 22 percent of the urban women and 7 percent of the rural women indicated that they were formally employed. In contrast, the majority of accompanying men at both the urban and rural sites reported being employed either part- or full-time. It is notable that no accompanying rural man reported being unemployed and, of the men followed up at home, all reported that they were either employed or in business.

Table 3 Occupation of respondents, by site*

\begin{tabular}{||l|l|l|l|l|l|l|l||}
\hline Respondents & Full-time job & Part-time job & Farming & Trader/small business & Student & Unemployed & Total \\
\hline Women at KNH & 66 & 20 & 26 & 54 & 14 & 123 & 303 \\
\hline Women at KPGH & 28 & 13 & 112 & 121 & 5 & 113 & 392 \\
\hline $\begin{array}{l}\text { Men accompanying } \\
\text { women at KNH }\end{array}$ & 67 & 22 & 4 & 26 & 2 & 1 & 122 \\
\hline $\begin{array}{l}\text { Men accompanying } \\
\text { women at KPGH }\end{array}$ & 26 & 13 & 13 & 14 & 1 & 0 & 67 \\
\hline $\begin{array}{l}\text { Men followed up at } \\
\text { KNH }\end{array}$ & 5 & 4 & 2 & 1 & 0 & 0 & 12 \\
\hline $\begin{array}{l}\text { Men followed up at } \\
\text { KPGH }\end{array}$ & 37 & 17 & 7 & 22 & 0 & 0 & 83 \\
\hline
\end{tabular}

* Some respondents did not answer the question.

Marital status. More than 80 percent of female respondents at both sites reported that they were in monogamous relationships (Table 4). Polygamous relationships, however, were more common at the rural site (16 percent) than they were in Nairobi ( 8 percent). The majority of accompanying males reported being in married, monogamous relationships. 
Table 4 Marital status of respondents*

\begin{tabular}{|c|c|c|c|c|c|c|c|}
\hline Respondents & $\begin{array}{l}\text { Married, } \\
\text { monogamous }\end{array}$ & $\begin{array}{l}\text { Married, } \\
\text { polygamous }\end{array}$ & $\begin{array}{l}\text { Cohabiting, } \\
\text { monogamous }\end{array}$ & $\begin{array}{l}\text { Cohabiting, } \\
\text { polygamous }\end{array}$ & $\begin{array}{l}\text { Not } \\
\text { committed }\end{array}$ & Other & Total \\
\hline Women at KNH & 214 & 17 & 33 & 5 & 0 & 0 & 269 \\
\hline Women at KPGH & 285 & 50 & 10 & 7 & 0 & 0 & 352 \\
\hline $\begin{array}{l}\text { Men } \\
\text { accompanying } \\
\text { women at KNH }\end{array}$ & 100 & 12 & 10 & 0 & 0 & 0 & 122 \\
\hline $\begin{array}{l}\text { Men } \\
\text { accompanying } \\
\text { women at KPGH }\end{array}$ & 55 & 10 & 0 & 2 & 0 & 0 & 67 \\
\hline $\begin{array}{l}\text { Men followed up } \\
\text { at KNH }\end{array}$ & 9 & 1 & 1 & 0 & 1 & 0 & 12 \\
\hline $\begin{array}{l}\text { Men followed up } \\
\text { at KPGH }\end{array}$ & 77 & 3 & 1 & 1 & 0 & 1 & 83 \\
\hline Providers at KNH & 64 & 4 & 7 & 0 & 5 & 2 & 82 \\
\hline $\begin{array}{l}\text { Providers at } \\
\text { KPGH }\end{array}$ & 69 & 5 & 5 & 0 & 0 & 1 & 80 \\
\hline
\end{tabular}

* Some respondents did not answer the question.

Approximately 30 percent of women at both sites reported having no living child, while onethird had three children or more.

Education. Educational attainment of female respondents was similar in the rural and urban settings: Only 3 percent of women had a college education, but a significant proportion (57 percent) had at least some primary education. In contrast, 38 percent of the men had at least some primary education, compared to 62 percent with a high school education or higher. The educational difference between female respondents and their partners is statistically significant (Chi square $\mathrm{p}<0.01$ at $1 \mathrm{df}$ ). Obviously, this has implications in terms of work opportunities and, therefore, economic independence and access to resources, which is reflected in the number of women who reported being unemployed and thus probably economically dependent on their partners.

Table 5 indicates the different cadres of service providers interviewed. At each site, the majority of providers were nursing officers. 
Table 5 Responding service providers, by cadre and site

\begin{tabular}{|l|l|l||}
\hline & KNH & KPGH \\
\hline Obstetrician/gynecologist & 9 & 2 \\
\hline Medical officer & 3 & 1 \\
\hline Clinical officer & 1 & 16 \\
\hline Nursing officer & 59 & 73 \\
\hline Social worker & 3 & - \\
\hline Other & 26 & 3 \\
\hline Total & 101 & 95 \\
\hline
\end{tabular}

The skew in the number of medical officers versus clinical officers is typical of the urban/rural dichotomy in Kenya and most developing countries.

\section{Reason for Current Hospital Visit}

In the rural setting, the majority of women had come for services related to pregnancy (antenatal care and delivery), while in the urban setting more women came for general $\mathrm{OB} / \mathrm{GYN}$ consultation and outpatient services (Table 6). In both the rural and the urban settings, very few women interviewed had come for STD/HIV treatment or infertility services. About half of all women interviewed came to the facility by public transport and the rest walked to the facility; implicit in this is that a large proportion came from a short distance away from the facility.

Table 6 Reason for current hospital visit $(\mathrm{N}=697)$

\begin{tabular}{||l|l|l|l|l|l|l|l|l||}
\hline Respondents & $\begin{array}{l}\text { Antenatal } \\
\text { care }\end{array}$ & $\begin{array}{l}\text { OB/GYN } \\
\text { consultation }\end{array}$ & Delivery & Infertility & $\begin{array}{l}\text { Family } \\
\text { planning }\end{array}$ & $\begin{array}{l}\text { STD/HIV } \\
\text { treatment }\end{array}$ & Other & Total \\
\hline Women at KNH & 29 & 120 & 54 & 9 & 86 & 0 & 5 & 303 \\
\hline Women at KPGH & 152 & 48 & 125 & 1 & 60 & 7 & 1 & 394 \\
\hline
\end{tabular}

\section{Presence of Partners for Current Visit}

When asked whether their partners were aware of their current hospital visit, 463 women (66 percent) responded in the affirmative, while 234 (34 percent) said their partners were not informed. Only one woman seeking infertility services said her partner was unaware of her visit to the hospital.

Of the 463 women who said their partners were aware of the current visit, only 187 (40 percent) were accompanied by their partners either at the time of the interview or at some point during their hospital visit (Table 7). Of these, most partners (77 percent) accompanied the women when they sought treatment for obstetrical and gynecological problems, or when they were in the maternity unit. Only 13 percent of women seeking antenatal care were accompanied by their partners. 
Table 7 Comparison of women accompanied versus those not accompanied, by service sought

\begin{tabular}{|l|l|l|l||}
\hline Service type & Accompanied & Not accompanied & Number of women \\
\hline Antenatal care & 25 & 95 & 120 \\
\hline OB/GYN consultation & 76 & 41 & 117 \\
\hline Delivery & 69 & 33 & 102 \\
\hline Infertility & 2 & 7 & 9 \\
\hline Family planning & 11 & 93 & 104 \\
\hline STD/HIV test/treatment & 2 & 3 & 5 \\
\hline Other & 2 & 4 & 6 \\
\hline Total women & 187 & 276 & 463 \\
\hline
\end{tabular}

\section{Reasons Partners Did Not Accompany Women}

Unaccompanied women were asked why their partners did not accompany them, and men who had not accompanied their partners were asked the same question when followed up. The trend of their responses was similar, as depicted in Table 8.

Table 8 Reasons given for not accompanying partners by unaccompanied women and men followed up in the community

\begin{tabular}{|l|l|l||}
\hline Reason & Unaccompanied women (\%) & Men followed up (\%) \\
\hline Man was working or otherwise occupied & 71.1 & 81.1 \\
\hline Man did not think it was necessary & 10.4 & 3.2 \\
\hline Man did not want to accompany woman & 9.2 & 4.2 \\
\hline $\begin{array}{l}\text { Woman did not want man to accompany } \\
\text { her }\end{array}$ & 8.6 & n.a. \\
\hline Man did not know about current visit & 28.0 & 10.5 \\
\hline
\end{tabular}

\section{Opinions on Male Involvement in Reproductive Health Services}

The study sought respondents' opinions as to what degree of male involvement is appropriate for various reproductive health services. Most respondents (95 percent of women and 99 percent of men) felt that some degree of partner participation was important.

In terms of actual service provision, both men and women considered it acceptable for men to accompany their partners for antenatal visits (90 percent); of these, 94 percent felt it was appropriate for men to be present during consultations. However, 45 percent of women and 40 percent of men felt that men should not be present during physical examinations.

Very few of the 146 women seeking FP services at the time of the interview were accompanied by their partners. In fact, only 5.8 percent of accompanying men did so for women seeking FP services. Most female respondents (89.2 percent) said that they would like their partners to be involved in seeking FP services, and, in support of this, more than 


\section{Figure 1 Service providers' perceptions regarding reproductive health activities at health facilities in which men should participate}
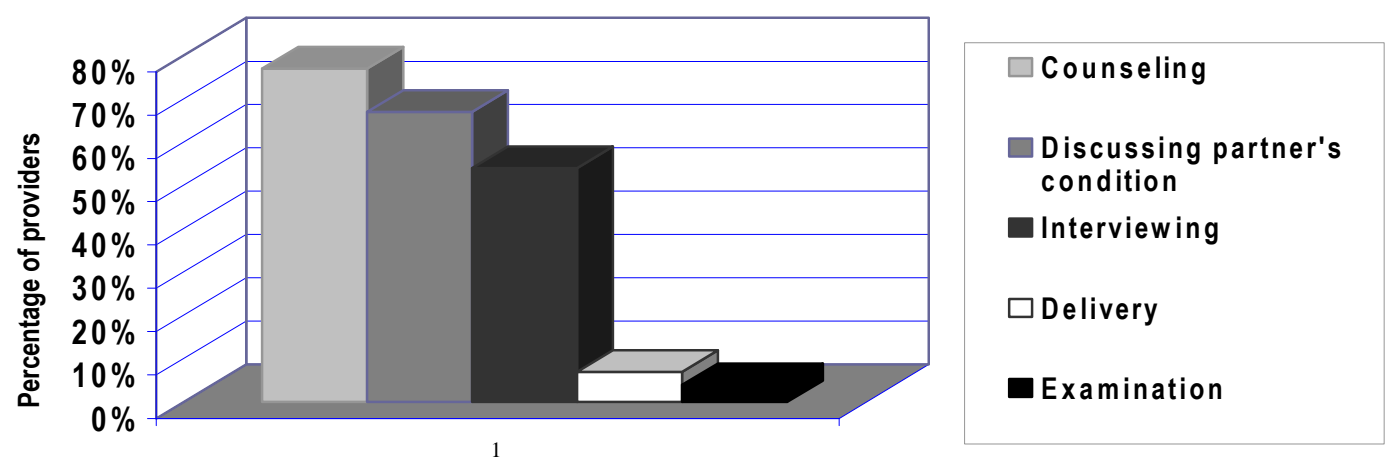

Activity

90 percent of male respondents who accompanied their partners to a facility said that they would also like to be involved in FP services. When asked specifically about antenatal care (ANC) 90 percent of all male respondents (those who accompanied their partners and those followed up) said they would like to be involved.

In terms of maternity care, more than 60 percent of both rural and urban men and women felt that the labor ward and delivery room should remain women's territory. Service providers felt similarly: They believed partners should be present during consultations but not during examinations or delivery (Figure 1).

When asked how men could participate in reproductive health services some respondents said that men should accompany their partners to all services, but there was variation in the degree of support for different categories of services. More than 90 percent of women and men were willing to have partners pay for services and be present during antenatal visits, consultations, and family planning. Few were willing, however, to have men present during examination, and even fewer (50 percent of women and 46 percent of men) felt that men should be in the labor ward or present during delivery (Table 9). The majority of women (96 percent) felt their partners should be present to handle the financial aspects of care.

Table 9 Desire by women and men to have partners participate in women's reproductive health services

\begin{tabular}{|l|l|l||}
\hline Service type & Female respondents (N=697) & Male respondents (N=284) \\
\hline Antenatal care & $632(91 \%)$ & $253(89 \%)$ \\
\hline Consultation & $655(94 \%)$ & $279(98 \%)$ \\
\hline Examination & $468(67 \%)$ & $183(64 \%)$ \\
\hline In the labor ward & $438(63 \%)$ & $176(62 \%)$ \\
\hline During delivery & $351(50 \%)$ & $132(46 \%)$ \\
\hline Postpartum visits & $644(92 \%)$ & $257(90 \%)$ \\
\hline FP clinic & $622(89 \%)$ & $246(87 \%)$ \\
\hline Pay for services & $669(96 \%)$ & $182(64 \%)$ \\
\hline
\end{tabular}


Service providers also welcomed the presence of male partners during consultation but not during examination. On the other hand, when asked about their own personal experiences when seeking reproductive health services, 70 percent of service providers said that they had either accompanied their partners (male providers) or had been accompanied by their partners (female providers) at some point when they were seeking reproductive health services. This finding was similar in both the rural and urban settings. Interestingly, more than 90 percent reported that their partners were present at the facility for deliveries although they may not have been present in the labor ward or delivery room (a distinction that was not specified in the questionnaires). Thus, while the service providers concurred that men should not be present in the maternity wards, in their own experience men were involved. This may indicate that providers and their partners use private facilities for delivery where there is less crowding and more privacy.

Despite the varied levels of actual partner participation, respondents provided suggestions as to how men's participation in reproductive health services could be enhanced (Table 10).

Table 10 Suggested ways to enhance partner support for women seeking reproductive health services, by respondent (percent)

\begin{tabular}{|l|l|l|l|l||}
\hline Suggestion & $\begin{array}{l}\text { Service } \\
\text { providers }\end{array}$ & Women & $\begin{array}{l}\text { Accompanying } \\
\text { men }\end{array}$ & $\begin{array}{l}\text { Followed-up } \\
\text { men }\end{array}$ \\
\hline Include partners in consultations & 88.3 & 94.1 & 96.8 & 96.8 \\
\hline $\begin{array}{l}\text { Provide partners with special consultation } \\
\text { when they accompany women }\end{array}$ & 41.3 & 28.1 & 29.6 & 35.8 \\
\hline Invite partners to the facility by themselves & 34.2 & 27.8 & 34.9 & 29.5 \\
\hline $\begin{array}{l}\text { Invite women and partners to the facility for } \\
\text { specific topics/meetings }\end{array}$ & 85.7 & 87.7 & 87.3 & 75.8 \\
\hline $\begin{array}{l}\text { Invite partners for special partners-only } \\
\text { meetings at the facility }\end{array}$ & 55.1 & 63.7 & 66.1 & 40.0 \\
\hline Follow up couples at home & 64.4 & 88.5 & 89.9 & 82.1 \\
\hline Hold community meetings & 74.0 & 75.3 & 78.3 & 80.0 \\
\hline
\end{tabular}

It is an assumption globally that improving couple communication will enhance partner support for women seeking reproductive health services, especially for family planning use and STD treatment. This study explored the link between partner support and discussion among couples of reproductive health issues. The data indicate that certain issues are discussed more than others (Table 11). Notably, sexual pleasure and protection against STDs/HIV were often mentioned by both the men and women interviewed. On the other hand, the issue of other sexual partners and individual reproductive health problems that might affect the other partner were not discussed very often. 
Table 11 Reproductive health issues commonly discussed by couples

\begin{tabular}{|l|l|l|l||}
\hline \hline Issue & Women (\%) & Accompanying men (\%) & Followed-up men (\%) \\
\hline When to have a child & 62.1 & 73.0 & 69.5 \\
\hline Ways to avoid pregnancies & 57.2 & 59.8 & 52.6 \\
\hline Methods of contraception & 56.0 & 59.8 & 51.6 \\
\hline Other sexual partners & 50.4 & 43.4 & 35.8 \\
\hline Sexual pleasure/enjoyment & 82.5 & 87.8 & 90.5 \\
\hline Protection against STDs/AIDS & 74.0 & 82.5 & 87.5 \\
\hline $\begin{array}{l}\text { Reproductive health problems the } \\
\text { woman may have experienced }\end{array}$ & 50.6 & 70.9 & 26.3 \\
\hline $\begin{array}{l}\text { Reproductive health problems the } \\
\text { man may have experienced }\end{array}$ & 44.0 & 65.6 & 30.5 \\
\hline Health of the children & 66.6 & 72.0 & 66.3 \\
\hline \hline
\end{tabular}

\section{Barriers to Partner Support at the Facility Level}

Beyond attitudes toward male participation it was critical to determine the accessibility of the facility and its services to accompanying partners. Accompanying partners were asked if they experienced any hindrance, physical or otherwise, within the facility during their current visit. Physical barriers did not appear to be an obstacle. A majority of men (77.2 percent) were able to talk to nurses, but few (12 percent) were able to talk with a doctor or clinical officer. A large proportion (76.1 percent) reported that they felt comfortable at the facility and only 1 percent reported any discomfort. The majority said they would be willing to come again. All accompanying partners reported that they arrived at their intended destination within the facility.

\section{FINDINGS FROM THE FOCUS-GROUP DISCUSSIONS}

To get a better understanding of both actual and potential behavior, FGDs were held with a different sample of female respondents (three groups in Kakamega and three in Kenyatta) and service providers (one group of nurses in Kakamega and one in Kenyatta). It was not possible to conduct FGDs with men as only a few accompanying partners were on the premises at any one time. None of the FGD participants had responded to the individual questionnaires. In general, the findings from the FGDs were similar to the information collected from the quantitative component, but the responses provided some clarification of the findings from the questionnaires.

\section{Partnership Expectations}

From the discussions it is evident that people enter into partnerships for a variety of reasons, including emotional satisfaction, economic support, procreation, and love and companionship. Of all the expectations, women ranked economic support highest, as it was felt that this is a man's role. It should be remembered, however, that most male partners of women participating in this study reported that they were working regularly in some capacity, in contrast to a majority of the women. 
With respect to health issues, female respondents further stated that the role men are expected to play in the event of a partner's ill health includes providing childcare, paying hospital bills and medication costs, and generally meeting the obligations of the household. Most women indicated that in general these expectations are fulfilled. Women observed that while some men are irresponsible, others are actually very eager to assist their partners. One of the FGD participants narrated her own experience:

I am not bragging, but I thank God because when I was pregnant and was operated on, my husband did his best. He was even bathing me and taking care of the children, even when they were sick. He used to hold the baby at night. I have seen him do things that other men cannot do.

The other participants conceded that there are always such exceptions.

\section{Perceptions of Actual and Desired Participation of Men}

Women participating in FGDs observed that when a family member is sick, women show greater concern. This attitude, they conclude, stems from their maternal role. As one put it, "It is the woman who undergoes the pain of giving birth, but a man can just leave a sick child on the bed and walk away. The mother stays home with the child." All focus groups maintained that the man's primary function in relation to women's reproductive health care is to provide financial assistance in terms of transport and payment of hospital bills.

The majority of the women participating in the FGDs had not been accompanied to the hospital by their partners even though they indicated that they would value such participation. According to them, a partner will only come to the hospital when he learns that the woman has a complication or that she is seriously sick and he thinks she will have to be admitted (which generally requires a prepayment prior to admittance). Under normal circumstances, women felt that as long as their partners give them the money required for transport, they need not play any other role. However, the same women indicated that they would like their partners to accompany them to the facilities, not only when they are ill, but also for services such as ante- and postnatal care. This reflects a contradiction that runs throughout the study results between what women expect in their current situation and what they would like in a hypothetical situation.

According to the women, many men are not inclined to come largely because they perceive such services as being for women only. For example, one woman said, "At times when men bring a baby for immunization they feel lost ... more so when they find the benches full of women. But often providers give them priority to be seen and they can go . . . this is good." According to the providers, most men feel uneasy in public hospitals where there are many women and where they are usually required to just "wait outside." Waiting time was also noted as another drawback to men's participation. Men say they keep away from health facilities because they end up staying there from "when the cleaning starts in the morning up to eleven o'clock in the morning." This leads men to the conclusion that accompanying their partners to health facilities is a waste of their time and explains why the routine of many men is to drop their partners off at the facility and then pick them up later. All the same, according 
to the service providers, some men do accompany their partners to antenatal clinics and even enter the maternity ward. They classify these men as being "civilized" or "Westernized."

In both rural and urban settings, service providers expressed the benefits of men accompanying their partners. Men would learn more about reproductive health matters; they would be able to better understand their partner's health condition; and the process might increase couple communication and thus strengthen their relationship.

The service providers indicated that first-time fathers are more likely to accompany their partners to the hospital than men who already have children. This may indicate that men may sometimes take greater care of their partners during the first pregnancy but "relax" as the woman becomes more experienced. It may also reflect changing perceptions of men's roles, especially among urban and predominantly nuclear families.

\section{Social and Institutional Constraints to Men's Participation}

All of the FGDs revealed that financial constraints are a major obstacle to men accompanying their partners to the hospital. For example, participants stated that bus fare for two people might not always be available or considered the best use of limited resources. Another constraint is that employers may not be willing to grant men permission to take time from work to accompany their partners. Employers have been heard to retort, "Mama anafanya nini? Anaweza kwenda pekee yake" [What does the woman do? She can go on her own.]. One of the FGD participants suggested that the man should be able to take paternity leave in order to help the woman at home. Another participant was quick to point out that having the man at home could actually result in greater stress for the woman because a man at home will want to be attended to by the woman rather than helping her out: "The woman will therefore have to handle two 'babies' at home - the man and the real baby. So, he had rather be away but provide financial support." Thus if it were a choice between the man earning income or accompanying the woman to the hospital, most women would opt for the man continuing to earn.

A number of other frequent constraints to men's participation emerged from the FGDs:

- Partners may not live together because the man is working far away from home;

- The man may be ignorant or unaware of the woman's situation due to poor communication between the partners; and

- Pride, cultural barriers, and peer pressure may be significant barriers to the man's participation.

Institutional factors also play a major role in inhibiting male participation, further exacerbating cultural and financial impediments. While in some cases men who accompany their partners are allowed in the consultation room, in public institutions they are not allowed in the examination room, labor ward, or delivery room. One reason given is lack of space for men, as facilities are already overcrowded, and men would disrupt the general routine in these areas. Given that there are often two women to a bed in the labor wards of public hospitals, it was felt that men would simply get in the way or loiter in the corridors, thus causing interference and inefficiency in hospital operations. 
Female participants in the FGDs acknowledged that space sometimes is a problem, but they noted that it is not so much the unavailability of space as the established hospital routine that results in partners not being allowed in these areas. Service providers admitted that it is not hospital policy to restrict men from these services; rather men are denied access because they are, in fact, not welcome. Men who come with their partners are often challenged at the admissions desk: "Wewe unaenda wapi?" [Where are you going?].

The survey results indicated that only 3.6 percent of service providers allowed men to be in attendance when they examined women, which appears to be representative of most public hospitals. The providers themselves noted that private hospitals do allow male partners into the wards and they themselves or their own partner were often present for the same series, including delivery. Some providers stated that they would actually like to allow male partners into clinics and wards, if both the couple and the provider agree, but that this is not practical in the present institutional setting where there is little if any privacy. For this to happen, they said that some changes in the actual configuration of services would need to take place.

Most of the women observed that the attitude of health service providers can negatively influence male involvement in the hospital, particularly in the area of reproductive health. Provider attitudes, they noted, varied from polite and encouraging (actually asking male partners to come back) to quite intimidating: "Kwani bibi yako hawezi kujileta?" [You mean your wife cannot bring herself?].

\section{Communication Between Partners}

Throughout the discussion women and providers alike raised issues of communication as a serious barrier to partner participation. Women emphasized that commitment is the key to couple communication, but that this is not always the case in many relationships. With regard to health issues, particularly those involving hospital visits, women reported that it is crucial for them to inform their partners prior to seeking services and discuss the visit upon their return home, regardless of whether men accompany them or not. Service providers reported that because both partners are affected in the case of STIs, it is more likely that male partners will accompany women to the clinic, indicating that men's participation can almost be guaranteed whenever their interests are immediately and directly involved.

Both health providers and female respondents felt that couple communication is enhanced when a man learns more about his partner's condition. In this way, he becomes more sympathetic and supportive. For this reason, a majority of the respondents in both the qualitative and the quantitative components of the study felt that men should be encouraged to participate to a greater extent in reproductive health care. 


\section{Strategies to Increase Male Participation Suggested by Study Participants}

Because of the complexity of the matter, various strategies were suggested to facilitate greater partner involvement. These included:

- Inviting partners to the clinic;

- Providing reading materials women could take home to their partners;

- Using community meetings (barazas) to reinforce these approaches;

- Broadcasting reproductive health information, including the advantages of men's participation, on the TV and radio; and

- Carrying out educational programmes at the men's place of work.

All these efforts, they felt, should help to demystify and defeminize reproductive health issues. Within the hospital setting, specific ideas derived from the survey data included the following:

- Include men in consultations when they accompany their partners to the hospital;

- Provide separate consultations for men when they accompany their partners;

- Invite men to the hospital by themselves;

- Invite men and their partners to special meetings on different topics;

- Invite men to participate in special men's meetings at the hospital;

- Visit men and their partners at home to discuss reproductive health issues; and

- Hold meetings on health topics with men within the community.

To facilitate this process, the providers recognized that they need to address their own attitudes toward clients, particularly male partners, as a prerequisite to encouraging greater male involvement. They felt that this could be done through refresher courses that focus on issues of human sexuality. Overall, from both the qualitative and quantitative responses, it was stressed that improvement in health service delivery was a crucial step toward achieving greater male participation in reproductive health.

\section{DISCUSSION}

\section{Myths About Men's Partnership}

There are many deeply ingrained notions within the reproductive health community on the subject of men's actual and potential involvement. For example, prior to carrying out this study we were told by many colleagues in Kenya that men do not accompany women to hospitals, yet there was no evidence to support or refute this assertion. We investigated the issue ourselves, and the results paint a much more positive and yet complex situation. We would like to address some of these common notions, or myths, about male participation in light of the findings from this study.

\section{What Do Women Want?}

The findings of this study confirm that people enter into partnerships for a variety of reasons, including emotional satisfaction, economic support, procreation, and love and companionship, among others. But of all the expectations the women participating in this 
study have for marriage, they ranked financial support highest, which reflects the profiles of respondents that show that, in both urban and rural areas, the majority of male partners were reported to be employed full or part time in contrast to the majority of women, who indicated that they were not employed. Not surprisingly, economic dependence and security are crucial concerns for these women.

The most important indication of a partner's support was his level of commitment to the relationship, regardless of whether the couple was residing together or the partner was away. This view resonated in discussions among both female respondents and service providers. Participants observed that companionship, though desired, sometimes was impossible as the male partner might be working away from home. Still, in such a case, the woman would be gratified knowing that he would provide financial and moral support in times of medical need along with regularly contributing to the household. Female respondents were quick to note that it was not a man's level of education but rather his degree of commitment to the relationship that determined whether or not he accompanied his partner. Female respondents preferred to think in terms of the quality of the relationship and personal attributes of their male partners, which go beyond their level of education.

From the FGDs, as well as the survey data, women indicated that men usually accompany them to the hospital when they learn that the woman has a complication or is seriously ill and that she will have to be admitted. However, in the case of serious gynecological problems, both sources indicated that women are more likely to be accompanied by their partners. Otherwise, for many of the women queried, the man has performed acceptably as long as he has given her the necessary money for transport, and he need not play any other role.

At the same time, when asked if they would they like to see their partners more involved, the majority of women answered in the affirmative. This probably means that what is actually possible and acceptable will be variable in terms of the situation of individual women and the nature of the service provided.

Expectations of partnerships are broad; however, the level at which these were fulfilled depended not only on the nature of the relationship between the partners but also the influence of their significant others, particularly with the extended family. However, on the whole, a positive relationship was seen as the key to fulfilling most of the expectations.

\section{Men's Participation in Reproductive Health Services}

The findings from this study indicate that men already do participate, at least to some degree, in women's reproductive health-seeking behavior. The factors that influence the type and degree of male participation appear to depend to a large extent on the nature of the visit. For example, the cultural perception of pregnancy and delivery as being normal states rather than disease means that they are perceived as ordinary female events that do not necessarily require male participation. Yet men are present at the time of delivery; however, this is most likely because payment of fees and/or purchase of commodities are required at this time. 
According to the service providers, 77 percent of first-time fathers accompanied their partners to the hospital, in contrast to 21.4 percent of men who were already fathers. This may suggest that men sometimes take greater care of their partners during the first pregnancy but relax as the wife becomes more experienced, or it may reflect changing attitudes among younger couples.

\section{Interest in and Willingness of Men to Accompany Women}

Data from the quantitative study indicate that 92.4 percent of female respondents and 89 percent of male respondents would like to see more male involvement in postpartum visits. Women also indicated that they would like their partners to accompany them to both antenatal and postnatal clinics, but the reality is that many men are not inclined to do this because they feel these services are for "women only."

The reasons given by women to explain why men do not accompany their partners to the hospital varied, but the most common were work-related (71.1 percent). According to the men who were followed up in the community, the most common reason they did not accompany their partners was that they were working or otherwise occupied (81.1 percent). This is, however, contradicted by the fact that 89 men who reported they were unemployed did not accompany their partners, while 127 men who were employed or otherwise occupied did.

It is, however, important to keep in mind that some women (8.6 percent) indicated that they did not want to be accompanied by their partners. During the FGDs women emphasized that this is the case particularly if the men are not their husbands or if they are older. According to the respondents, some men are very comfortable and feel responsible for their partners, while others feel out of place and fear "what other people will say." Others fear they will be regarded as idlers. In addition, the community does not hold in high esteem men who accompany their partners unnecessarily; they are perceived as either having nothing else to do or showing off.

Respondents indicated that men accompanying their partners to the hospital might be viewed as admirable, or they might expose the partner to ridicule. For example, FGD participants noted that some jealous people might say the man is "amekaliwa" (henpecked) or is "showing off," or they might say, "Kwani huyu bwana hana kazi nyingine ya kufanya?" [Does this man not have any work to do?] or "Kwani huyu mama hawezi kujipeleka clinic?" [Can't this woman take herself to the clinic?]. Not surprisingly, community opinion that considers hospital visits women's domain labels men who accompany their wives as idlers or henpecked. Many men experience discomfort or are fearful, either of the service provider or of being seen "walking around" with their women, which is culturally unacceptable. Structural and attitudinal constraints at the individual, societal, and health-facility level therefore play a major role in keeping men away. In defense of men who do not accompany their partners, 63 percent of the male respondents who had accompanied their partners reported that some men could not take time off from work, while 50.3 percent said that some men are afraid to accompany their partners. According to the quantitative and qualitative data, men who accompany their wives tend to be younger, first-time fathers, employed, professionals, and in monogamous unions. 
It was also acknowledged that certain circumstances might make it difficult for men to accompany their partners, such as inability to pay for transportation for the woman and her partner. Therefore, if the man feels he is not required at the hospital and the woman is not seriously sick, he does not feel he must accompany her. In the FGDs, providers agreed with female respondents that men often do not accompany their partners to the hospital, not so much because they will be laughed at, but because this is the way they have been socialized. Men feel that women should go to the hospital alone while they take care of the family, although this is not always the case, especially in situations where men are employed.

Although they may accompany their partners to the hospital to help explain problems to the doctor, men are usually not allowed to stay in the room when their partners are being examined. This is shown clearly by the perception of providers, women, and men who responded to the question, "When should a partner be present during reproductive health service provision?" The majority in all groups felt the man should be present during interviewing (consultation) but not for examination or delivery. Women felt that the doctor could explain the diagnosis to the male partner afterward.

It is evident from this study that partners' presence during delivery and while patients are being examined is not a popular way of involving men in the reproductive health equation, at least within public hospitals. This is even confirmed by responses obtained on self-practice by service providers, where 82 percent and 74 percent of accompanying partners participated in consultation and counseling, respectively, but only 6 percent were present during examination of their partners. ${ }^{2}$

Partnerships are sensitive to both internal and external factors, including economic conditions and culture. They are strongly influenced by support or obstruction from key individuals in positions of power and authority. In this study, the extended family, especially the mother-inlaw, was noted as creating a major obstacle to partnering, particularly when she lived in the same household, as was commonly reported. On the other hand, participants acknowledged that there were instances where the extended family was very supportive.

\section{Couple Communication Regarding Reproductive Health Matters}

The degree and quality of couple communication seems to be heavily dependent on the relationship between the mother-in-law and her son and between the mother-in-law and her daughter-in-law (sometimes it is the mother-in-law who accompanies a woman to the hospital). When the relationship is positive, the bonds between the couple are strengthened. When the relationship is strained, it almost always has a negative impact on couple interaction as the man is under pressure to submit to the demands of his mother. In addition, a strained relationship is more likely when the couple and the extended family reside in close proximity. Therefore, women in the Kakamega focus groups were affected more by the role of the mother-in-law than those in the urban setting where, presumably, interaction with the extended family is minimized.

\footnotetext{
${ }^{2}$ Service providers were not asked about partner presence during delivery.
} 
A majority of women indicated that they discuss their health condition with their partners on return from the hospital. This tallies with the quantitative data that show that about 90 percent of the men who were followed reported that their partners had discussed the hospital visit with them. In the case of STDs, both sources of data revealed that partners discussed their situation and sought medical intervention. The quantitative data also showed that over 70 percent of the respondents interviewed (excluding service providers) reported that they discussed protection against STDs and AIDS.

The study also revealed that providers can hinder or facilitate couple communication. In the case of STD treatment, confidentiality requires providers to leave partner notification to the man or woman seeking treatment. In other areas of reproductive health, providers often inadvertently perpetuate the traditional notion of reproductive health being largely a female issue. For example, when men escort their partners, they are often made to feel out of place if not outright ridiculed. A classic example cited by a number of respondents is that when a man escorts his wife to the labor ward and attempts to go beyond the admission desk, the hospital staff will always ask whether he is "also in labor." During the discussions, the providers conceded that they are responsible for some of these problems because of the way they interact with clients. Similarly, women reported that health providers often ask their partners what reason they have to be at the clinic, thus reinforcing cultural norms and stereotypes.

\section{Is Reproductive Health a Woman's Domain?}

Reproductive health has traditionally been considered a woman's domain, couched in mystery and unwelcoming to male intrusion. While it is evident that overcrowding and limited physical space are issues, it is also clear that women and health providers (who are predominantly female) are concerned with notions of social space, boundaries, and privacy, which define the levels at which male partners are allowed to participate in reproductive health.

The real and perceived boundaries to male participation vary from service to service. ANC and consultations are more open and men can be included, at least to a limited extent. However, participation becomes more problematic in the labor and delivery wards. Few of the women interviewed were in support of men being present in the labor ward, either because of concern that men would see the nakedness of other women, or because they felt men have no significant role to play at this point. Others concurred that partners could provide comfort at this time, but ultimately did not feel this was a strong enough reason for their presence.

With regard to delivery, a majority of the women were quite adamant that it is solely a woman's affair and therefore should be closed to male participation; their feelings had nothing to do with issues of physical space. Women agreed that a woman needs privacy at this time,

even from her husband. They said they preferred that other women be present as they would be able to draw from shared experience. This tallies with the finding in the survey that more than 90 percent of both men and women were of the opinion that the man's role in delivery should be to take care of financial needs. However, there were a few respondents among both women and service providers who were inclined toward male presence during labor and delivery. 
Women's views about what services should allow male participation are supported by health providers. Presence of partners during consultation is allowed and even favored by many providers in order to facilitate communication and avoid misunderstandings related to diagnosis and patient management. For example, a woman may be advised to take complete bed rest to avoid a miscarriage, or certain prescriptions may necessitate a special diet, but her husband often asks "Ni daktari gani huyo anasema ule nyama pekee?" [Which doctor is this who says you should eat only meat?].

The providers reported that partners are never present during examinations of pregnant women. Some stated that the men are usually around, but are not allowed into the examination room. In fact, in the survey only 3.6 percent of providers said that they allow men to be in attendance during patient examination. In contrast, throughout the FGDs service providers indicated that the man needs to be with his partner while she is being examined to be aware of what is going on.

Providers stated that the inclusion of men was not limited only by space constraints. Even if a cubicle was available for each woman, providers would still not include men because there are certain procedures they would not want relatives to witness. Here it is apparent that service providers themselves are uncomfortable with the possibility of observation, so they imagine their clients will also be uncomfortable. Thus it may be that the reason women said they did not want their partners to be present during labor and delivery was partly due to provider attitudes as well as physical constraints.

\section{CONCLUSION AND RECOMMENDATIONS}

The results of this study clearly show that, to a larger extent than anticipated, men in Kenya already participate in women-centered reproductive health services. For the majority of women interviewed, the man's financial responsibility for her care was their primary concern; many men accompanied their partners to the facilities in order to pay fees. On the other hand, both the women and men interviewed thought that men should and could be more involved, especially in consultations and counseling. The benefit of partners knowing about and understanding women's health status was seen as highly valuable.

Not surprisingly, the structural and attitudinal constraints at the health facilities were seen as playing a major role in keeping men away; "There is no place for them" was a common refrain. Furthermore, delays at the facility clearly deter male participation. It was very interesting to find that while men's involvement with work was the most frequently cited reason for their not accompanying their partners, all but one of the men who did accompany their partners reported that they were employed. The idea that men regard reproductive health as a woman's affair resonated in the discussions across the groups as well as in the findings of the quantitative survey.

Overall the institutional barriers seemed to be more overwhelming than the cultural barriers, given that one of the reasons frequently given for nonparticipation was fear of non-acceptance by the health providers. Service providers in general were supportive of the idea of greater participation by men in the interviewing and counseling stages, but not during physical 
examinations or in the wards. They frequently cited the crowded conditions as a major deterrent, noting the men would actually get in the way of their providing services. However, when asked about their personal practice, most male partners of female providers and male providers had played a much more active role in the health care of their partners, including during delivery. While the question was not specifically asked, it is most probable that these providers go to private facilities for services, which are less crowded and more open to partner participation, indicating that providers may not be so resistant to the idea of greater partner involvement but have not really thought about how it might be possible within their own work situations. On the other hand, they may not be willing to be observed as they conduct examinations, which, in reproductive health practice, may expose a client's sensitive body parts.

\section{Implementing What Has Been Learned}

Based on the results of this study, we are planning to carry out one or possibly two interventions in early 2000. The development of these interventions would actively involve all the groups (women, men, and providers) who participated in this study as well as higherlevel medical personnel and members of the community. In this way, the degree of increased men's participation will be one that is currently acceptable to all of the players. We believe that if it then becomes clear that partner involvement can have a positive effect on service delivery and the couple's relationship, there will be receptivity to moving another step ahead, possibly as far as involving fathers in labor and delivery.

Throughout any such exercise, it will be important to be respectful of the instances in which a woman, for any reason, does not wish for her partner to be more involved.

\section{Potential Levels for Interventions}

Based on the Population Council's work on social context issues, including partnership, three potential levels for interventions have been developed:

Level I: Providing information on partnership for reproductive choice and health

Level II: Building comfort and capacity among providers

Level III: Creating a space for partners

The results of this study indicate that there are opportunities for interventions at all three levels, although, as noted above, the space for partners may remain limited to consultations and outpatient care for at least the immediate future. 